\title{
Effets de l'extrusion de graines oléo-protéagineuses sur la composition lipidique du lait chez la vache
}

\author{
M Focant, A Legrand, E Mignolet, M Vanbelle
}

Université catholique de Louvain, place Croix-du-Sud, 2 (8), 1348 Louvain-la-Neuve, Belgique

L'extrusion des aliments favorise la complexation des lipides avec l'amylose et avec les protéines (Izzo et Ho, 1989). Par ce travail, nous avons vérifié l'effet de cette complexation sur l'hydrogénation des graisses dans le rumen et sur la composition en acides gras (AG) du lait.

Quatre vaches Frisonne-Holstein en pleine lactation portant une canule ruminale et duodénale ont été utilisées dans un schéma en crossover pour tester 2 rations de composition identique ( $54 \%$ ensilage de maïs, $18 \%$ pulpes sèches, $27 \%$ concentrés, $2 \%$ CMV; sur la base de la MS). Elles différaient par le traitement du concentré : mouture ou extrusion à $160^{\circ} \mathrm{C}$ (extrudeur monovis Wenger). Le concentré contenait $40 \%$ de pois, $30 \%$ de graines de soja, $20 \%$ de graines de colza et $10 \%$ de manioc.

Les vaches ont ingéré, en moyenne, 17,6 \pm $1,2 \mathrm{~kg}$ de MS par jour. Les AG représentaient environ $5 \%$ de la ration et provenaient pour $80 \%$ du concentré. L'extrusion de celui-ci n'a pas modi- fié leur composition (en moyenne 85\% AG insaturés). Au niveau du duodénum, les AG en $\mathrm{C} 18$ ont été significativement $(P<0,05)$ moins saturés avec le régime "concentré extrudé". La proportion de C18:0 a été diminuée de $22 \%$ et celle de C18:1 a été augmentée de $72 \%$. L'extrusion du concentré a augmenté la production laitière, et le taux butyreux a diminué. L'insaturation plus prononcée des AG duodénaux s'est répercutée essentiellement sur la teneur du lait en C18:1 (+34\%). La concentration en C16:0 a eu tendance à diminuer avec le concentré extrudé.

En conclusion, l'utilisation d'un concentré extrudé à base d'oléoprotéagineux a eu une forte tendance à accroître la teneur en acide oléique et à diminuer la teneur en acide palmitique dans le lait. Ceci devrait avoir pour conséquence une meilleure "tartinabilité" du beurre sortant du réfrigérateur.

Izzo MT, Ho CT (1989) Cereal Chem 66, 47-51

Tableau I. Composition en acides gras dans le duodénum et dans le lait.

\begin{tabular}{|c|c|c|c|c|}
\hline & gime moulu & Régime extrudé & $S D D^{*}$ & $P^{* *}$ \\
\hline \multicolumn{5}{|c|}{ Acides gras dans le duodénum (\% des AG totaux) } \\
\hline $\mathrm{C} 16: 0$ & 13,7 & 13,1 & 0,6 & 0,40 \\
\hline C18:0 & 59,0 & 46,2 & 3,7 & 0,04 \\
\hline C18:1 & 18,0 & 31,0 & 2,8 & 0,02 \\
\hline C18:2 & 7,2 & 7,2 & 0,7 & 0,95 \\
\hline $\mathrm{C} 18: 3$ & 1,2 & 1,7 & 0,1 & 0,03 \\
\hline $\mathrm{kg}$ lait/] & 24,6 & 28,0 & 1,6 & 0,10 \\
\hline Taux butyreux (\%) & 3,5 & 3,0 & 0,3 & 0,19 \\
\hline \multicolumn{5}{|c|}{ Acides gras dans le lait (\% des AG totaux) } \\
\hline $\mathrm{C} 16: 0$ & 36,3 & 28,7 & 3,4 & 0,11 \\
\hline C18:0 & 7,8 & 10,3 & 1,5 & 0,21 \\
\hline C18:1 & 24,8 & 33,3 & 3,8 & 0,11 \\
\hline C18:2 & 3,7 & 4,5 & 0,4 & 0,12 \\
\hline C18:3 & 0,5 & 0,7 & 0,1 & 0.17 \\
\hline
\end{tabular}

\footnotetext{
"Déviation standard de la différence ; "* niveau de signification.
} 